\title{
Prevalence of thrombocytopenia in Parturient: Experience in Tertiary Care Center
}

\author{
Shashikala Karanth ${ }^{1}$, Shruthi K. ${ }^{2, *}$, Sheela C. N. ${ }^{3}$, Cecil Ross ${ }^{4}$ \\ ${ }^{1}$ Associate Professor, ${ }^{2}$ Senior Resident, ${ }^{3,4}$ Professor, ${ }^{1,2,3}$ Dept. of Obstetrics and Gynecology, ${ }^{4}$ Dept. of Medicine, St. John's \\ Medical College and Hospital, Bengaluru, Karnataka, India
}

*Corresponding Author:

Email: shrukalagara@gmail.com

\begin{abstract}
Introduction: Thrombocytopenia can result from a wide range of conditions with several of them being pregnancy related. Obstetricians manage most cases of pregnancy-associated thrombocytopenia. Thus, a working knowledge of the clinical features and management of thrombocytopenia in pregnant women is important. The objective of the study was to evaluate the causes of thrombocytopenia and its effect on maternal and neonatal outcome in parturient women and also evaluate the obstetric risk factors, complications, and outcome of pregnancies complicated by thrombocytopenia.

Materials and Methods: A prospective study of 100 antenatal women with thrombocytopenia who delivered at St John's Medical College Hospital during a one and a half year period. The blood samples of pregnant women in labor room were collected at the time of admission. These women were followed up till they deliver. Results: The main causes of thrombocytopenia were hypertensive disorders: preeclampsia (15\%), Hemolysis, elevated liver enzymes, and low platelets (24\%) and eclampsia (4\%); idiopathic thrombocytopenic purpura (16\%), gestational thrombocytopenia (11\%). Women with hypertensive disorders had higher rates of cesarean delivery $(65 \%)$, intrauterine growth restriction (30\%) and preterm deliveries (31\%). Hemorrhagic complications are common in rarer causes of thrombocytopenia.

Conclusion: The adverse outcome is specifically attributed to preeclampsia, HELLP syndrome and rare causes. While the perinatal outcome of GT and ITP is basically favorable. Careful surveillance is required for these women in high-risk units for early detection and treatment of possible complications, in order to reduce adverse maternal and neonatal outcomes.
\end{abstract}

Keywords: Thrombocytopenia, Partueient, Preeclampsia, HELLP, Gestational thrombocytopenia.

\section{Introduction}

Thrombocytopenia can be defined as platelet count less than $150,000 / \mu \mathrm{L}$ or platelet count below the $2.5^{\text {th }}$ percentile for pregnant patients. Thrombocytopenia complicates 7 to $10 \%$ of all pregnancies. ${ }^{1}$ The normal range of platelets in non-pregnant women is 150,000 $400,000 / \mu \mathrm{L}$. Average platelet count in pregnancy is decreased $180,000-213,000$ versus $250,000 / \mu \mathrm{L} .^{2}$

Classification of thrombocytopenia in pregnancy is similar to non-pregnant patients. Mild thrombocytopenia is $100,000-150,000 / \mu \mathrm{L}$. Moderate thrombocytopenia is $50,000-100,000 / \mu \quad$ L. Severe thrombocytopenia is $<50,000 / \mu \mathrm{L} .^{3}$ Thrombocytopenia can result from a wide range of conditions with several of them being pregnancy related. Physiological decrease in platelet count is due to hemodilution, increased platelet consumption, and increased platelet aggregation (increased levels of thromboxane A2). ${ }^{4}$

Most common cause of thrombocytopenia reported by several authors is gestational thrombocytopenia (70$80 \%)$ followed by hypertensive disorders $(15-20 \%)$, idiopathic thrombocytopenic purpura (1-4\%) and other rare causes. ${ }^{2,3}$ The diagnosis of specific disorder is often difficult because the time of onset of these disorders during pregnancy and their clinical manifestations often overlap.

Obstetricians manage most cases of pregnancyassociated thrombocytopenia. Thus, a working knowledge of the clinical features and management of thrombocytopenia in pregnant women is important. Most instances of thrombocytopenia are benign, but pregnancy related conditions may cause morbidity or even death if not treated promptly. Severe neonatal thrombocytopenia is infrequent; however, the incidence varies according to the causes of maternal thrombocytopenia

The present study was aimed to study the prevalence and etiology for thrombocytopenia in parturient women and its effects on maternal and perinatal outcome, and also to evaluate the obstetric risk factors, complications and outcome of pregnancies complicated by thrombocytopenia due to various aetiologies.

\section{Materials and Methods}

A prospective observational study was carried out in Department of Obstetrics \& Gynaecology, St Johns medical College and hospital, Bengaluru, Karnataka, India, for one and a half year, after obtaining institutional ethical committee clearance.The study included parturient women with thrombocytopenia admitted in the Labor room and those who gave written and informed consent for the study. Thrombocytopenia was identified by computerized hematology laboratory report. Women who had undergone splenectomy earlier were excluded.

The following maternal characteristics were evaluated: age of mother, gestational age, parity, past 
medical and menstrual history. Clinical characteristics and obstetrical risk factors which includes preeclampsia, placental abruption, labor induction, mode of delivery, postpartum hemorrhage ( $\mathrm{PPH}$ defined as a blood loss $>500 \mathrm{~mL}$ in vaginal deliveries and $>1000 \mathrm{~mL}$ in cesarean deliveries), disseminate intravascular coagulopathy (DIC defined as platelet count $<100 \times 10^{9} / \mathrm{L}$, decreased fibrinogen, and elevated D-dimer and fibrin degradation products), requirement of blood and blood product transfusion. Fetal outcome which includes birth weight, fetal death, intrapartum fetal distress, 1-minute and 5-minute Apgar scores, admission to the neonatal intensive care unit(NICU), thrombocytopenia in new born, platelet transfusion and neonatal death were studied. All patients were followed up till the delivery.

\section{Statistical Analysis}

Data was entered in Excel and the analysis was done using SPSS version 23. Continuous variables were reported using mean +/- standard deviation for the normally distributed variables otherwise median and inter quartile range were used. Categorical variables were reported using number and percentages. Chisquare test was done to test the association between outcomes with categorical variables. All the analysis was considered statistically significant at 5\% level (P value $<0.05$ ).

\section{Results}

A total of 4,441 patients delivered in labor ward of St Johns Medical College and Hospital during the study period. During the study 100 pregnant women with thrombocytopenia delivered 103 neonates; there were 3 twin deliveries. Mean maternal age was $26.37 \pm 4.87$ years. Most women with gestational thrombocytopenia and hypertensive disorders were 21-25 years and women with idiopathic thrombocytopenic purpura (ITP) were $26-30$ years. $52 \%$ of patients were nulliparous and $48 \%$ were multiparous.

A distribution of the thrombocytopenia according to their etiology is presented in table 1 .

The results were analyzed into four groups to assess the maternal and perinatal outcome in each group

1. Hypertensive disorders

\section{ITP}

3. GT

4. Others

Women with preeclampsia, HELLP (hemolysis, elevated liver enzymes, low platelet count) syndrome and Eclampsia were grouped into pregnancy related hypertensive disorders. Women with mild to moderate thrombocytopenia without other identifiable etiology were classified as gestational thrombocytopenia (GT). Women with severe thrombocytopenia with normal blood pressure were classified into ITP after ruling out infection. Women grouped into others include dengue fever, vitamin B12 deficiency, hypersplenism (EHPVO- extra hepatic portal venous obstruction and NCPF- non-cirrhotic portal fibrosis), acute fatty liver of pregnancy (AFLP), disseminated intravascular coagulation (DIC), antiphospholipid antibody syndrome (APLA syndrome), aplastic anemia, systemic lupus erythematosus (SLE) and heparin induced thrombocytopenia (HIT).

Platelet range among the groups is shown in Figure 1. Majority of women with hypertensive disorders $(55.8 \%)$ and GT $(45.5 \%)$ had moderate thrombocytopenia.

Among the medical risk factors anemia was the most prevalent (24\%) as shown in table 2. Obstetric risk factors include PROM (8\%), previous cesarean (7\%), gestational diabetes (3\%) and multiple pregnancies (3\%).

Maternal complications (table 3) like PPH (30\%) and DIC (26.7\%) were higher in rarer etiologies. Higher rates of blood transfusion $(66.7 \%)$ and ICU admission $(30 \%)$ were also observed in this group. Requirement of blood and blood products during delivery and in postpartum period is shown in table 4 .

There were 103 neonates in this study. Preterm deliveries were $58(56.3 \%)$. Of these $32(31 \%)$ were from hypertensive disorders group. The mean birth weight was least among hypertensive disorders $(1798.33 \mathrm{~g} \pm 748.33 \mathrm{~g})$. IUGR, low APGAR at 1 minute and NICU admission and neonatal thrombocytopenia were more common in the hypertensive disorder group compared with the other etiologies Neonatal outcome and complications are listed in table 5 .

Table 1: Distributions of the thrombocytopenia according to their etiology

\begin{tabular}{|l|c|c|}
\hline \multicolumn{1}{|c|}{ Etiology } & No. of pregnant women & Percent \% \\
\hline Preeclampsia & 15 & 15.0 \\
\hline HELLP syndrome & 24 & 24.0 \\
\hline Eclampsia & 4 & 4.0 \\
\hline ITP & 16 & 16.0 \\
\hline GT & 11 & 11.0 \\
\hline Dengue fever & 9 & 9.0 \\
\hline Vitamin B12 deficiency & 4 & 4.0 \\
\hline Hypersplenism & 4 & 4.0 \\
\hline AFLP & 3 & 3.0 \\
\hline
\end{tabular}




\begin{tabular}{|l|c|c|}
\hline DIC & 3 & 3.0 \\
\hline APLA & 2 & 2.0 \\
\hline Aplastic anemia & 2 & 2.0 \\
\hline SLE & 2 & 2.0 \\
\hline HIT & 1 & 1.0 \\
\hline
\end{tabular}

Table 2: Maternal risk factors according to etiologies

\begin{tabular}{|l|c|c|c|c|}
\hline Characteristics & $\begin{array}{c}\text { Hypertensive } \\
\text { disorders(n=43) }\end{array}$ & ITP(n=16) & GT(n=11) & $\begin{array}{c}\text { Others } \\
(\mathbf{n = 3 0})\end{array}$ \\
\hline Previous CS & $4(9.3 \%)$ & $2(12.5 \%)$ & 0 & $1(3.3 \%)$ \\
\hline Anemia & $8(18.6 \%)$ & 0 & 0 & $16(53.3 \%)$ \\
\hline GDM & $1(2.3 \%)$ & 0 & $1(9.1 \%)$ & $1(3.3 \%)$ \\
\hline IUGR & $29(67.4 \%)$ & $4(25 \%)$ & $1(9.1 \%)$ & $12(40 \%)$ \\
\hline PROM & $1(2.3 \%)$ & $3(18.8 \%)$ & $2(18.2 \%)$ & $2(6.7 \%)$ \\
\hline Hypothyroidism & $2(4.7 \%)$ & $3(18.8 \%)$ & $2(18.2 \%)$ & $1(3.3 \%)$ \\
\hline
\end{tabular}

Table 3: Maternal complications according to etiologies

\begin{tabular}{|l|c|c|c|c|}
\hline \multicolumn{1}{|c|}{ Characteristics } & $\begin{array}{c}\text { Hypertensive } \\
\text { disorders(n=43) }\end{array}$ & ITP(n=16) & GT(n=11) & $\begin{array}{c}\text { Others } \\
(\mathbf{n = 3 0})\end{array}$ \\
\hline Placental abruption & $4(9.3 \%)$ & 0 & 0 & $3(10 \%)$ \\
\hline PPH & $1(2.3 \%)$ & $3(18.8 \%)$ & 0 & $9(30 \%)$ \\
\hline DIC & $1(2.3 \%)$ & 0 & 0 & $8(26.7 \%)$ \\
\hline Blood transfusion & $17(39.5 \%)$ & $12(75 \%)$ & $3(27.3 \%)$ & $20(66.7 \%)$ \\
\hline ICU admission & $6(14 \%)$ & $1(6.3 \%)$ & 0 & $9(30 \%)$ \\
\hline Maternal mortality & 0 & 0 & 0 & $2(0.6 \%)$ \\
\hline
\end{tabular}

Table 4: Blood transfusion among women according to etiologies

\begin{tabular}{|l|c|c|c|c|}
\hline \multicolumn{1}{|c|}{ Characteristics } & $\begin{array}{c}\text { Hypertensive } \\
\text { disorders } \\
(\mathbf{n = 4 3})\end{array}$ & ITP $(\mathbf{n = 1 6})$ & $\begin{array}{c}\text { GT } \\
(\mathbf{n = 1 1})\end{array}$ & $\begin{array}{c}\text { Others } \\
(\mathbf{n = 3 0})\end{array}$ \\
\hline Platelet transfusion & $10(23.3 \%)$ & $12(75 \%)$ & $3(27.3 \%)$ & $17(56.7 \%)$ \\
\hline Packed cell & $9(20.9 \%)$ & $2(12.5 \%)$ & 0 & $14(46.7 \%)$ \\
\hline FFP & $2(4.7 \%)$ & $1(6.3 \%)$ & 0 & $10(33.3 \%)$ \\
\hline
\end{tabular}

Table 5: Neonatal complications among different groups

\begin{tabular}{|l|c|c|c|c|}
\hline \multicolumn{1}{|c|}{ Characteristics } & $\begin{array}{l}\text { Hypertensive } \\
\text { disorders } \\
(\mathbf{n = 4 5})\end{array}$ & ITP(n=16) & GT(n=12) & $\begin{array}{l}\text { Others } \\
(\mathbf{n = 3 0})\end{array}$ \\
\hline $\begin{array}{l}\text { Gestational age at } \\
\text { delivery < 37 weeks }\end{array}$ & $32(71.1 \%)$ & $7(43.7 \%)$ & $4(33.3 \%)$ & $15(50 \%)$ \\
\hline MSAF & $4(8.9 \%)$ & $3(18.8 \%)$ & 0 & $3(10 \%)$ \\
\hline IUGR & $31(68.9 \%)$ & $4(25 \%)$ & $1(8.3 \%)$ & $12(40 \%)$ \\
\hline NICU admission & $30(69.8 \%)$ & $7(46.7 \%)$ & $3(27.3 \%)$ & $12(50 \%)$ \\
\hline $\begin{array}{l}\text { Neonatal } \\
\text { thrombocytopenia }\end{array}$ & $8(17.7 \%)$ & $8(50 \%)$ & 0 & $3(10 \%)$ \\
\hline $\begin{array}{l}\text { Neonatal platelet } \\
\text { transfusion }\end{array}$ & $1(4.3 \%)$ & $3(21.4 \%)$ & 0 & 0 \\
\hline
\end{tabular}

Table 6: Comparison of Neonatal complications

\begin{tabular}{|l|c|c|c|}
\hline \multicolumn{1}{|c|}{ Characteristics } & $\begin{array}{c}\text { Parnas M }^{\text {et }} \mathbf{a l}^{\mathbf{8}} \mathbf{( \% )}\end{array}$ & $\begin{array}{c}\text { Varghese S et } \\
\mathbf{a l}^{\mathbf{7}} \mathbf{( \% )}\end{array}$ & Present study \\
\hline Neonatal thrombocytopenia & $\mathrm{n}=7$ & 0 & $18.44(\mathrm{n}=19)$ \\
\hline $\begin{array}{l}\text { Neonatal platelet } \\
\text { transfusion }\end{array}$ & $\mathrm{n}=1$ & 0 & $3.88(\mathrm{n}=4)$ \\
\hline IVIG & 0 & 0 & 0.97 \\
\hline MSAF & 12.1 & - & 9.7 \\
\hline
\end{tabular}




\begin{tabular}{|l|c|c|c|}
\hline Delivery $<37$ weeks & 25.6 & 29.6 & 56.31 \\
\hline APGAR at $1 \mathrm{~min}<7$ & 16.8 & 3.1 & 29.78 \\
\hline APGAR at $5 \mathrm{~min}<7$ & 8.7 & 3.1 & 8.54 \\
\hline
\end{tabular}

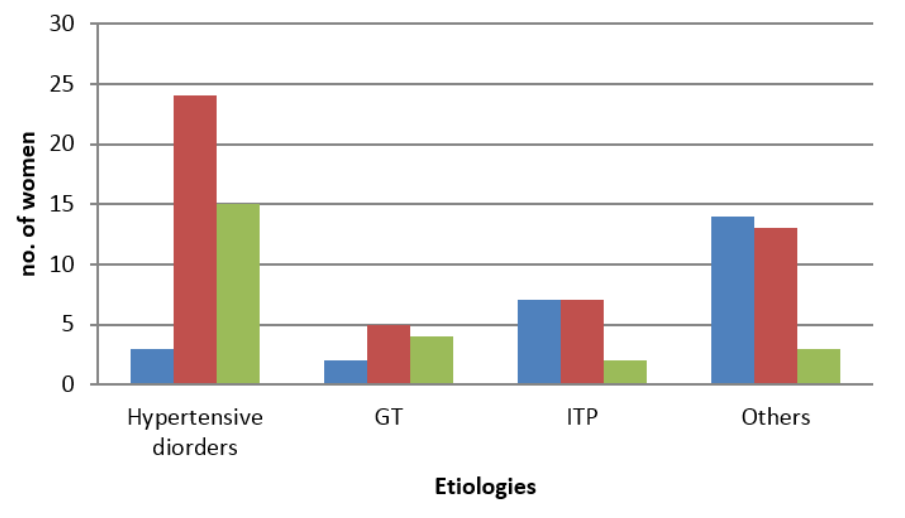

platelet range $/ \mu \mathrm{L}$

- $<50000$

—50000-100000

=100000-150000

Fig. 1: Severity of thrombocytopenia according to etiologies

\section{Discussion}

Thrombocytopenia in pregnancy is a challenging task for obstetricians. Decreased platelet count may be a pregnancy induced disorder or a preconceptional condition. The main differential diagnosis that may be difficult to separate until after delivery are GT and ITP as both are diagnosis of exclusion. This study was aimed at investigate etiology, obstetric risk factors, maternal and neonatal outcomes of pregnancies complicated by thrombocytopenia.

Prevalence of thrombocytopenia in our study is $2.25 \%$ while Nisha $\mathrm{S}$ et $\mathrm{al}^{2}$ observed $8.8 \%$ and Varghese $\mathrm{S}$ et $\mathrm{al}^{5}$ reported $4.2 \%$.

In our study group mean maternal age was $26.37 \pm$ 4.87 years this is similar to those of Varghese $\mathrm{S}$ et al and Parnas $M$ et al study., ${ }^{5,6}$ There were 52\% nulliparous and $48 \%$ multiparous women in our study. This finding is similar to Varghese $\mathrm{S}$ et al study ${ }^{5}$ whereas in Parnas $M$ et al study, majority of them were multiparous $(78.1 \%)^{6}$

In our study majority of women had moderate thrombocytopenia (49\%) at the time of delivery, $26 \%$ had severe thrombocytopenia and $25 \%$ had mild thrombocytopenia this is in contrast to other studies where they observed mild to moderate thrombocytopenia during delivery time. . $^{2,5}$,

The aim of management in these cases is to achieve and maintain a 'safe' rather than normal platelet count. An experienced team and an individualized approach are important. Current recommendations aim for a platelet count of $\geq 50000$ prior to labor and delivery as the risk of caesarean delivery is present with every labor. Corticosteroids may improve the platelet count and other laboratory parameters more quickly and is indicated mainly in ITP and HELLP. ${ }^{3,10}$ In our study 14 women with ITP received antenatal and intrapartum steroids (prednisolone or dexamethasone) 19 women with HELLP syndrome received steroids (dexamethasone) for an average of 3 days. Whereas Nisha et $\mathrm{al}^{2}$ study reported that none of the patient required steroid in their study.

The mode of delivery must be based on obstetric considerations; there is no evidence that Caesarean section is safer for the fetus with thrombocytopenia than an uncomplicated vaginal delivery, which is usually safer than caesarean section for the mother. ${ }^{7}$ In our study higher rate of IOL (induction of labor) in women with hypertensive disorder (23\%), mainly in HELLP syndrome was noted because the definitive treatment is to deliver. $49 \%$ women had caesarean section in this study. Several studies reported similar incidence. ${ }^{6-8}$ Presence of medical and obstetric risk factors did not have any influence on maternal and neonatal outcome in these patients. This finding is similar to Nisha et al study.

In this study $56.31 \%$ delivered preterm, whereas Nisha $\mathrm{S}$ et $\mathrm{al}^{2}$ observed $31.8 \%$ preterm deliveries. The difference could be because of higher incidence of hypertensive disorders in the present study. Many reports observed higher rates of preterm deliveries in patients with moderate to severe thrombocytopenia. ${ }^{4,6-}$ 8,11 Our study also had a similar finding.

In this study, $52 \%$ women with thrombocytopenia received blood and blood products. Among them 17 women had hypertensive disorders $(n=43), 12$ of them had ITP $(n=16)$ and 3 had gestational thrombocytopenia $(\mathrm{n}=11)$. Varghese $\mathrm{S}$ et $\mathrm{al}^{5}$ reported $25 \%$ and Parnas et $\mathrm{al}^{6}$ reported $16.6 \%$ of women with thrombocytopenia required blood transfusions. Major bleeding requiring multiple blood and blood products transfusion occurred in 13 women. Majority of them are belonging to rarer causes for thrombocytopenia (DIC, AFLP, APLA syndrome, Vitamin B12 deficiency). Interestingly women in hypertensive disorders did not have 
significant bleeding; it is probably the result of careful surveillance and treatment. Placental abruption (7\%), PPH $(4.3 \%)$ and DIC (9\%) were the most common maternal complications noted in our study .Cesarean Section incision site oozing and wound hematoma were not observed in our study ,as compared to M Arora study. ${ }^{8}$ Nisha et $\mathrm{al}^{2}$ reported $9.98 \% \mathrm{PPH}$ in their study.

16 women required ICU care in our study. Most of these patients were booked outside and were referred to our institute for tertiary care. Majority of them had thrombocytopenia due to rarer causes (DIC, AFLP, APLA syndrome or Vitamin B12 deficiency.)

It is known that GT is not associated with an increased incidence of pregnancy-related complications or with the delivery of a thrombocytopenic offspring, similarly in this study GT is not associated with increased maternal or perinatal complications. . $^{1,5,6,11}$

There were two (2\%) maternal deaths in our study as compared to Nisha $\mathrm{S}^{2}$ et al and Usha et al ${ }^{11}$ where they reported $5.26 \%$ and $4.37 \%$ maternal mortality. One death was due to AFLP and another one was due to APLA. Mortality in AFLP is secondary to sepsis, renal failure or due to circulatory collapse and mortality in APLA is due to cerebral involvement but not due to thrombocytopenia alone. ${ }^{12}$ Early recognition, prompt delivery and intensive supportive care are essential to optimize maternal and fetal prognosis in these conditions.

Preterm deliveries and IUGR were the commonest fetal complications observed in this study, most of them were in hypertensive disorders group. These findings are similar to Parnas $\mathrm{M}$ et $\mathrm{al}^{6}$ study.

Neonates may be at increased risk for thrombocytopenia. Usha et $\mathrm{al}^{11}$ and Dwivedi et $\mathrm{al}^{9}$ reported no neonatal complications in their studies. In the present study a total of nineteen infants were thrombocytopenic, eight of them were born to mothers with hypertensive disorders and ITP and one each to mothers with SLE, dengue fever and hypersplenism. There was no major bleeding although three infants born to mothers with ITP had severe thrombocytopenia; two infants received platelet transfusion and one infant received both platelet transfusion and intravenous immunoglobulin (IVIG).

Our study showed higher perinatal mortality rate 119/1000 (11 cases) which can be attributed to preterm delivery. Two stillbirths each were noted in mothers with HELLP syndrome and placental abruption with DIC, one each in mothers with AFLP, ITP, aplastic anemia and vitamin B12 deficiency. One intrapartum death was seen in mother with AFLP. Two neonates born to mothers with HELLP syndrome were discharged against medical advice; both are included in postpartum death. These observations are similar to previously published studies. ${ }^{6,7,11,14}$

Perinatal outcomes are compared with other studies as shown in table 6.

\section{Conclusion}

The common cause of thrombocytopenia in pregnancy in this study is mainly hypertensive disorders (43\%), followed by ITP (16\%) and GT (11\%). Patients with GT and ITP have favorable maternal and perinatal outcomes. On the other hand, preeclampsia and HELLP syndrome are associated with adverse perinatal outcome like IUGR (30\%) and stillbirths.

The rarer and more serious group of causes of thrombocytopenia are associated with adverse outcomes like placental abruption, blood transfusions, MICU admissions, low Apgar scores (<7) at 1 and 5 min, and stillbirths.

Careful surveillance is required for these women in high-risk units for early detection and treatment of possible complications, in order to reduce adverse maternal and perinatal outcomes.

\section{References}

1. Perepu U, Rosenstein L. Maternal thrombocytopenia in pregnancy. Proceedings of Obstet Gynecol.2013;3(1):1 15.

2. Nisha S, Amita D, Uma S, et al. Prevalence and characterization of thrombocytopenia in pregnancy in Indian women. Indian Journal of Haematology and Blood Transfusion 2012;28(2):77-81.

3. Gernsheimer T, James A, Stasi R. How I treat thrombocytopenia in pregnancy. Blood. 2012;121(1):3847.

4. Anca Marina, Simona Colibaba,Brandusa Cimpoca, George Peltecu, AncaMaria Thrombocytopenia in pregnancy; Medica-a journal of clinical medicine;2016;11(5)55-60.

5. Shiny Varghese, Gagandeep Kour, Tapasya Dhar Thrombocytopenia in pregnancy in a tertiary care hospital:a retrospective study; Int J Reprod Contracept Obstet Gynecol. 2016 May;5(5):1532-5.

6. Parnas M, Sheiner E, Shoham. Moderate to severethrombocytopenia during pregnancy. Eur J Obstet Gynecol Reprod Biol. 2006;128:163-8.

7. Myers B.Diagnosis and management of maternal thrombocytopenia in pregnancy ; British J Haematology;2012;158;3-15

8. Arora M, Goyal L, Khutan H.Prevalence of Thrombocytopenia during Pregnancy \& Its Effect on Pregnancy \& Neonatal Outcome. Ann. Int. Med.Den. Res. 2017; 3(2):ME04-ME06.

9. Dwivedi P, Puri M. Nigam A. et al. Fetomaternal outcome inpregnancy with severe thrombocytopenia. European Review for Medical and Pharmacological Sciences. 2012; American Society of Hematology16: 1563-6.

10. 2013 Clinical Practice Guide on Thrombocytopenia in Pregnancy; American Society of Hematology.

11. Usha S, Renuka P, Vandana P. Prospective study of thrombocytopenia in pregnancy and its effect on maternal and foetal outcome. J. Evid. Based Med. Healthc. 2016; 3(82), 4463-4469

12. Giannakopoulos BKrilis S. The Pathogenesis of the Antiphospholipid Syndrome. New England Journal of Medicine. 2013;368(11):1033-1044

13. Cervera R, Khamashta M, Shoenfeld Y, Camps M, Jacobsen S, Kiss E et al. Morbidity and mortality in the antiphospholipid syndrome during a 5-year period: a 
multicentre prospective study of 1000 patients. Annals of the Rheumatic Diseases. 2008;68(9):1428-32.

14. Perinatal Mortality- What has changed? [Internet]. Indianpediatrics.net. 2016 [cited 3 October 2016]. Available from:

http://www.indianpediatrics.net/mar2016/mar-242-

243.html. 